\title{
Brenda Dunn-Lardeau, Le voyage imaginaire dans le temps. Du récit médiéval au roman postmoderne
}

\section{Francesca Forcolin}

\section{(2) OpenEdition}

1 Journals

\section{Edizione digitale}

URL: http://journals.openedition.org/studifrancesi/7077

DOI: 10.4000/studifrancesi.7077

ISSN: 2421-5856

\section{Editore}

Rosenberg \& Sellier

\section{Edizione cartacea}

Data di pubblicazione: 1 septembre 2010

Paginazione: 421-422

ISSN: 0039-2944

\section{Notizia bibliografica digitale}

Francesca Forcolin, «Brenda Dunn-Lardeau, Le voyage imaginaire dans le temps. Du récit médiéval au roman postmoderne», Studi Francesi [Online], 161 (LIV | II) | 2010, online dal 30 novembre 2015, consultato il 08 janvier 2021. URL: http://journals.openedition.org/studifrancesi/7077 ; DOI: https:// doi.org/10.4000/studifrancesi.7077

Questo documento è stato generato automaticamente il 8 janvier 2021.

\section{(c) $(1) \odot$}

Studi Francesi è distribuita con Licenza Creative Commons Attribuzione - Non commerciale - Non opere derivate 4.0 Internazionale. 


\title{
Brenda Dunn-Lardeau, Le voyage imaginaire dans le temps. Du récit médiéval au roman postmoderne
}

\author{
Francesca Forcolin
}

\section{NOTIZIA}

BRENDA DUNN LARDEAU, Le voyage imaginaire dans le temps. Du récit médiéval au roman postmoderne, Ellug, Grenoble, 2009, pp. 385.

Dall'antichità all'epoca contemporanea, gli scrittori si sono sempre confrontati con la Storia e con i limiti dell'esperienza umana di fronte al divenire del Tempo, fino ad accostare nella diegesi epoche diverse e lontane tra loro, trasgredendo così le regole della linearità e della concezione temporale.

2 Nello spazio della finzione romanzesca epoche lontane possono ricongiungersi, unirsi, giustapporsi; i personaggi viaggiare oltre i limiti del tempo grazie a un sogno, all'immortalità (tema ricorrente nell'antichità cristiana e nei testi di alchimia), alla reincarnazione o con l'ausilio di oggetti magici, scendere negli Inferi come Orfeo e Dante.

Da qui lo studio dei testi eterocronici (termine coniato da Michel Foucault per designare romanzi in cui coesistono due o più epoche storiche) di cui il volume si propone di analizzare l'evoluzione, i metodi usati per mettere in relazione passato e presente, nonché gli effetti prodotti alla lettura. La compresenza di epoche si realizza perlopiù attraverso viaggi nel tempo da parte dei personaggi, o mediante il ricorso dell'autore a volontari arcaismi, all'utilizzo del linguaggio di un'altra epoca, al racconto alternato. Interessanti risultano le modalità adottate da Virginia Woolf in Orlando, largamente analizzato nel IV capitolo, romanzo storico - letto anche come biografia fittizia - in cui il protagonista accumula in sé l'esperienza di molteplici vite nell'arco di quattro secoli, nonché di due sessi, come sottolineò Roger Caillois. 
4 Nei sette capitoli di cui è composto il volume, si analizzano cronologicamente alcune opere considerate significative, dal più antico roman hétérochronique, La legende des sept dormants del v secolo, passando per Montesquieu, ai racconti fantastici del XIX secolo, all'Orlando fino al romanzo "postmoderno" con Carlos Fuentes e Robertson Davies. Uno studio approfondito e comparatistico che si appoggia sulle teorie di Georges May, Elisabeth Wesseling e Milan Kundera, per citarne alcuni.

Il volume si apre con l'«Introduction. L'hétérochronie fictionnelle» (pp. 7-40), suddivisa in paragrafi: L'hétérochronie, Brève genèse de l'utilisation de l'hétérochronie dans les récits, Récits fondateurs, À partir du XIX siècle, Un cas particulier: le personnage hétérochronique dans un récit qui ne l'est pas, Variété des modalités de l'hétérochronie, Points de vue critiques utiles à l'interprétation des récits hétérochroniques, Corpus examiné et présentation des cuvres étudiées.

6 Il primo capitolo analizza «La légende des sept Dormants ou la traversée du Temps» (pp. 41-66); è composto dalle sezioni: Bilan hagiographique, La légende des sept Dormants dans la culture littéraire et l'imaginaire contemporains, Conclusion.

7 Segue «Histoire véritable de Montesquieu» (pp. 67-90), suddivisa in D'Histoire véritable de Lucien de Samosate (II siècle) à Histoire véritable de Montesquieu; Réincarnation et métamorphose dans Histoire véritable; Le jeu de la vérité et de la fiction dans Histoire véritable; Le voyage imaginaire comme moyen pour le comparatisme; Conclusion.

8 La terza parte, "L'hétérochronie dans la littérature fantastique du XIX ${ }^{\mathrm{e}}$ siècle» (pp. 91-146), comprende Le fantastique: une littérature de transgression; Stratégies hétérochroniques en sphère fantastique; Expériences fantastiques et hétérochroniques chez Washington Irving; Conclusion.

9 Il quarto capitolo, «Orlando ou l'enjambée des siècles d'un élisabéthain» (pp. 147-186), è composto dai paragrafi Orlando comme roman historique; Orlando comme biographie fictive; Orlando comme roman d'inspiration autobiographique; Orlando comme roman hétérochronique; Conclusion.

Il quinto, «Traversées du temps et de l'histoire» (pp. 187-210), comprende Le temps à une échelle individuelle et collective; Un immortel à travers le temps et l'Histoire; Représentations de l'Histoire dans sa longue durée; Le passé mis en relation avec le présent; Conclusion.

11 Il penultimo, «Reconstructions du temps et de l'His-toire» (pp. 211-246), è suddiviso in Les personnages hétérochroniques; Les objets producteurs d'hétérochronie; Les jeux avec le temps; La relecture de Vico par Fuentes et ses effets sur la représentation de l'Histoire dans Terra Nostra; Conclusion: un roman historique hétérochronique au service d'une polyphonie de l'Histoire.

12 Nel settimo e ultimo capitolo, «Visions hétérochroniques du monde» (pp. 247-280), troviamo i paragrafi L'inscription du passé dans le présent; Les finalités de l'hétérochronie dans Les anges rebelles; Conclusion.

13 Chiude il volume «Conclusion sous forme d'essai» (pp. 281-292), e un'ampia bibliografia, suddivisa in «Bibliographies compilées» (pp. 293-318), «Bibliographie commentée de romans hétérochroniqes» (pp. 319-374), «Index» (pp. 375-385). 